\title{
Denaverine hydrochloride and carbetocin increased welfare during and after parturition and enhanced subsequent fertility in cattle
}

\author{
Robert Zobel $^{* 1}$ and Juhani Taponen $\dagger^{1,2}$ \\ *Department of Agriculture, Sisacko-Moslavacka County, A. i B. Radića 24, 44000 Sisak, Croatia \\ †Department of Production Animal Medicine, Faculty of Veterinary Medicine, University of Helsinki, Paroninkuja 20, FI-04920 Saarentaus, Finland
}

\section{ABSTRACT}

The objectives of the current study were to investigate the influence of denaverine hydrochloride and carbetocin on softening and dilatation of the birth canal, the need for assistance during parturition, calf mortality, retention of fetal membranes, endometritis, and subsequent fertility. Altogether 200 animals (100 cows and 100 heifers) of the Simmental breed were divided into 2 groups: treatment $(\mathrm{n}=100)$ and control $(\mathrm{n}=100)$. Animals in the treatment group received denaverine hydrochloride and carbetocin (a maximum of twice for each, depending on the progression of labor) during delivery over a maximum of 4 waiting periods (30 min each), whereas control animals experienced the same waiting periods but received no treatment. The treatment protocol had a positive influence on the ease of calving and postpartum reproductive health. The treatment increased the number of animals with the birth canal dilated by more than $25 \mathrm{~cm}$, and halved the need for any assistance at parturition. In addition, treatment decreased the occurrence of difficult calving, the need for episiotomy, the appearance of birth canal lesions, and clinical endometritis. The treatment protocol had an effect throughout the entire puerperal period, as treated animals conceived with fewer artificial inseminations (1.3 vs. 1.6 artificial inseminations/pregnancy) and sooner (67 vs. $78 \mathrm{~d}$ open) compared with control animals. Denaverine hydrochloride and carbetocin administered in combination during parturition affected the progression and ease of calving, and thus the welfare of cows in labor and subsequently. However, further studies are needed to confirm the findings and to establish best practices.

Key words: cattle, denaverine hydrochloride, parturition, welfare

Received September 27, 2013.

Accepted February 26, 2014.

${ }^{1}$ Both authors contributed equally to the manuscript.

${ }^{2}$ Corresponding author: juhani.taponen@helsinki.fi

\section{INTRODUCTION}

All pain compromises animal welfare, and dystocia was ranked as one of the most painful conditions in cattle by cattle practitioners in the United Kingdom (Huxley and Whay, 2006). Other veterinary practitioners ranked pain due to dystocia as 7 on a 10-point scale, where 10 represented the maximum pain (Whay et al., 2008). Some Scandinavian countries have proscribed the use of double-muscled cattle breeds and restricted the use of mechanical calf pullers to veterinarians to reduce suffering and pain during delivery (Mee, 2008).

Obstetrical assistance less than $1 \mathrm{~h}$ after the appearance of the fetal hooves increases the risk of prolonged assistance, dystocia, use of a calf puller, downer cow syndrome, and reduced perinatal vigor. The delay of assistance for more than $2 \mathrm{~h}$ increases the duration of calving and induces hyperlactatemia in the neonate without conferring any additional benefits (Egan et al., 2001; Mee, 2004). Duration of second-stage labor of $2 \mathrm{~h}$ can be tolerated by heifers and cows providing normal position and posture of the fetus can be maintained (Gundelach et al., 2009). The occurrence of dystocia, however, increases culling and mortality rates (McClintock, 2004), stillbirth (Mee, 2004), and the risk of respiratory and digestive disorders in both the cow and calf, as well as retained placenta, uterine diseases, mastitis, and hypocalcaemia (Oltenacu et al., 1988; Lombard et al., 2003, 2007). Cows that experience dystocia are more likely to experience it again during subsequent calving (Mee et al., 2008). The total cost of dystocia was assessed to be 4 times greater than the treatment costs alone when the costs of the consequences of dystocia listed previously were included (Oltenacu et al., 1988).

Denaverine hydrochloride (DH) is a neurotropic-musculotropic spasmolytic agent with additional analgesic activity (Hüller, 1970; Scharein and Bromm, 1998). It is used in the treatment of smooth muscle spasms of the gastrointestinal and urogenital tract (Hüller, 1970), as well as in the treatment of postoperative abdominal pain and in the field of obstetrics. According to the instructions, DH softens the birth canal soft tissue, has an anesthetic effect on its surface, and increases the in- 
fluence of carbetocin (CT; Staab et al., 2003); however, very little has been published on DH effects.

It is commonly known that oxytocin increases the frequency of uterine contractions and strengthens them during parturition (al-Eknah and Homeida, 1991), and contractions can be fortified with exogenous administration of oxytocin. Oxytocin stimulates contractions at least by increasing prostaglandin release (with which it has a synergistic effect) and by increasing $\mathrm{Ca}^{2+}$ concentration (MacKenzie and Burns, 1997). The administration of oxytocin during parturition, or within $2 \mathrm{~h}$ after, can prevent placental retention (Squire, 1980; Miller and Lodge, 1984; Roberts, 1986; Fields and Fields, 1996; Mollo et al., 1997; Drillich et al., 2007), although contradictory views on the effects were reported (Arthur, 1979; Hickey et al., 1984). It has been estimated that the total pregnancy rate in cows with retained placenta is reduced by approximately $15 \%$ compared with that for unaffected cows (Fourichon et al., 2000).

A prolonged uterotonic effect can be achieved by using agonistic analogs of oxytocin with longer biological activity, such as CT (Cort et al., 1979; Eulenberger et al., 1986; Bernhard et al., 1993; Sobiraj et al., 1998). The uterotonic effect of a single intramuscular administration of either oxytocin (50 IU) or its long-acting agonist CT $(0.35 \mathrm{mg})$ were compared in a field study on early postpartum dairy cows after normal parturition (LeBlanc, 2008). It transpired that both drugs significantly increased the frequency and strength of uterine contractions, mainly during the first posttreatment hour. However, the uterotonic effects were almost equal, and a prolonged effect of CT could not be demonstrated.

The principal aim of the current study was to explore means to decrease pain and injury during parturition to improve cattle welfare. The detailed objectives were to study the influence of DH on softening and dilatation of the birth canal (primary cervix and vulva), and to study the effects of DH followed by administration of $\mathrm{CT}$ on the need for assistance during parturition and on calf mortality. In addition, consequences of these treatments were studied on retention of fetal membranes and endometritis rates, as well as on subsequent fertility.

\section{MATERIALS AND METHODS}

\section{Animals}

The study was performed on 11 commercial dairy farms in the central region of Croatia (SisačkoMoslavačka County), each with 30 to 100 Simmental cows. The management was similar on all farms and the average annual milk yield ranged between 5,168 and 6,689 $\mathrm{kg}$. Lactating cows, dry cows, and heifers were housed separately in freestalls, in groups of 30 to 90 animals, with the possibility to graze during the day from March until November. During the cold period, animals also had the possibility to go out voluntarily. Animals were fed hay ad libitum. Twice a day a concentrate consisting of barley, oats, corn, soybean, and minerals mixed with straw and silage made of corn and grass was provided. Propylene glycol was added to the ration of high-yielding animals (cows tended to produce more than $6,000 \mathrm{~kg} /$ lactation).

Before the experiment began, all pregnant animals were scored for body condition according to Edmonson et al. (1989) from 2 to 5 mo of pregnancy. Only those animals with a BCS between 2.5 and 3.5 were included; the rest were excluded due to the possible influence of obesity or poor condition on the results. In addition, animals suffering from diseases such as polyarthritis, recurrent mastitis (animals having mastitis more than once during previous or current lactation), increased SCC (>200,000 cells/mL of milk) for more than 3 mo during previous or current lactation, or laminitis, as well as animals having extremely defective construction of hind limbs or previous caesarean section and animals given birth by the time of arrival or having had twins, were excluded for the same reason. Animals were divided randomly into 2 groups, treatment $(\mathbf{T})$ and control (C), with cows and heifers separated. Animals were included in the experiment to assemble 100 cow- and heifer-calving cases. The parity of cows varied between 1 and 7 at the beginning of the experiment, being on average 4.3 and 4.4 in groups $\mathrm{T}$ and $\mathrm{C}$, respectively. The experiment was conducted from May 2008 until June 2009.

\section{Experimental Protocol}

The cattle owners were directed to call for 1 of the 3 veterinarians involved in the study to be present immediately after detection of any signs of incipient parturition. The inclusion criteria explained previously were checked once again, and animals not fulfilling criteria were excluded. After thorough obstetric examination, the diagnosis of parturition was established based on cervix opened more than $10 \mathrm{~cm}$ with several signs of obvious distress in the cow (excessive restlessness, repeatedly lying down and standing up, lateral recumbency, vocalization, repeated abdominal muscle contractions, repeatedly raising the tail). To measure dilatation of the vulva and cervix, fingers (side by side) of 1 or 2 hands were inserted and, if not sufficient, a fist of 1 or both hands were inserted first into the vulva horizontally, stretching the canal to its maximum extent, and then comparing the magnitudes against 


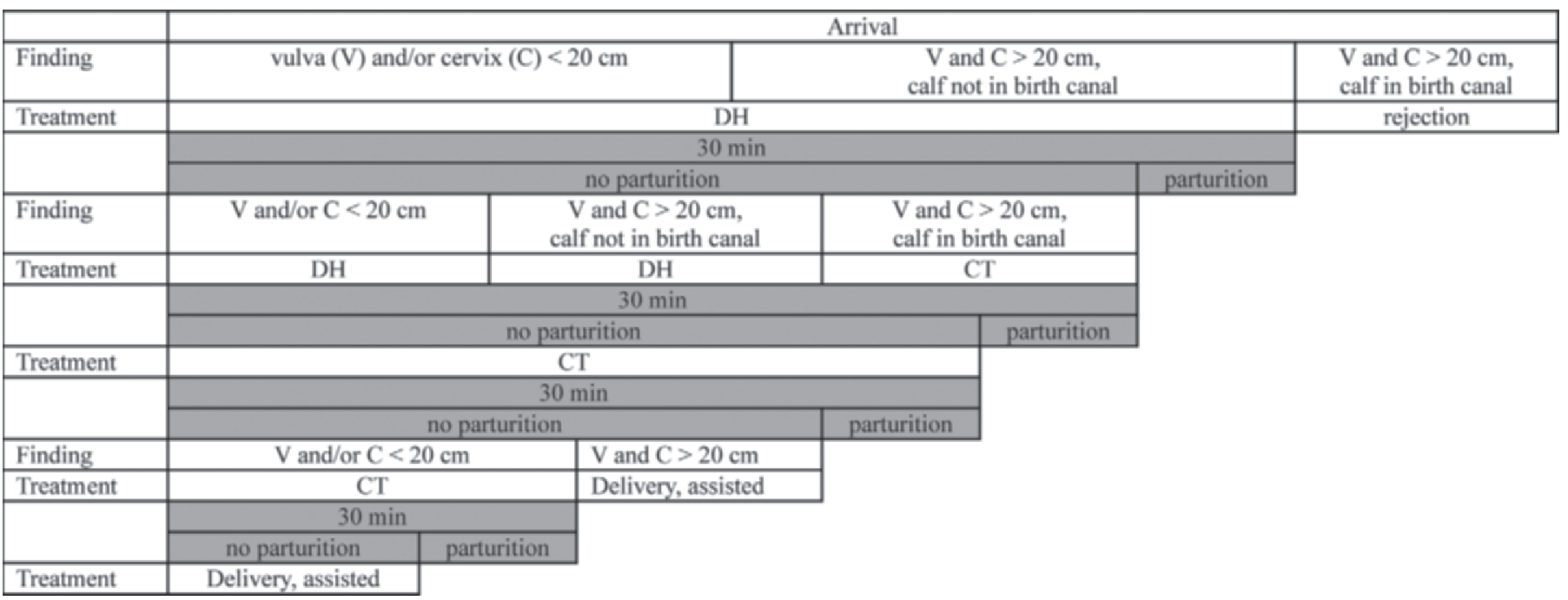

Figure 1. Schematic presentation of the treatment protocol for group T. The protocol for group C was exactly the same, but no medical treatments were given. $\mathrm{DH}=$ denaverine hydrochloride; $\mathrm{CT}=$ carbetocin.

a ruler. Thereafter, the same operation was repeated deeper in the cervix. If the vulva or cervix were dilated more than the width of 2 fists, the fingers of 1 or both hands were spread horizontally and inserted and data were compared against a ruler. The veterinarians involved practiced the method before and also during the experiment to guarantee repeatability of the method. The accuracy of the method was evaluated to be $2 \mathrm{~cm}$. The cases for which the vulva and cervix were dilated by more than $20 \mathrm{~cm}$ and a calf was in the birth canal, or cases with abnormal position or posture of the fetus, uterine torsion, or other pathological conditions of the birth canal were excluded from the experiment.

A detailed treatment protocol is presented in Figure 1. In brief, after the obstetric examination, the animals allocated to group $\mathrm{T}$ were immediately administered $400 \mathrm{mg}$ of DH i.m. and were left alone for $30 \mathrm{~min}$. Animals that had not given birth after the waiting period were reexamined and, depending on the progression of the parturition, a second dose of $\mathrm{DH}$ or $0.35 \mathrm{mg}$ of $\mathrm{CT}$ i.m. was administered and the animal was left alone for a further $30 \mathrm{~min}$. After the second waiting period, all animals that had not given birth received $0.35 \mathrm{mg}$ of CT i.m. and were left alone for the third waiting period of $30 \mathrm{~min}$. Thereafter, the calves of all animals with vulva and cervix dilated more than $20 \mathrm{~cm}$ were delivered with assistance, whereas the rest received the second dose of $0.35 \mathrm{mg}$ of CT i.m. and were left alone for 30 min. Finally, after the maximum of 4 treatments and waiting periods of $30 \mathrm{~min}$ each (120 min in total), animals were obstetrically examined and all calves were delivered by assistance. The animals of group $\mathrm{C}$ were examined and handled exactly as the animals of group $\mathrm{T}$, except no medical treatments were given.
All deliveries were monitored, the use of CT was assessed by the veterinarian, and necessary assistance was provided under veterinary control. The effect of the treatment on the softening of the birth canal was evaluated as a proportion of animals having a vulva or cervix dilated more than $25 \mathrm{~cm}$ at parturition. The time from the first examination to delivery was recorded. The ease of calving was evaluated and divided into 2 categories: delivery with or without assistance. The deliveries by assistance were further divided into 2 categories. Stage I assistance included the cases where light traction, considered as help of 1 or 2 persons, was applied. The cases where more power, moderate to hard traction, was needed were classified as stage II assistance. Some of these cases can be classified as dystocia. In 5 heifers, 2 in group $\mathrm{T}$ and 3 in group $\mathrm{C}$, a caesarean section was performed due to feto-maternal disproportion. Despite the fact that the treatment was unlikely to have an effect on the cases of clear feto-maternal disproportion, all the cases were included in the material to keep it unselected. The need for episiotomy was evaluated following the appearance of the fetal head and hooves into the vestibulum. The dilation was measured by inserting a flat hand between the forehead and dorsal commissure of the vulva. In cases where the insertion was impossible, episiotomy was performed to prevent possible lacerations and birth canal lesions.

Following the birth, calves were weighed and cows gynecologically examined using vaginoscopy and intravaginal palpation to evaluate possible lesions of the birth canal and the possible presence of a twin calf. The lesions were treated surgically and with antibiotics applied parenterally and locally. Calf mortality was followed during the first $24 \mathrm{~h}$ after birth. 
During the first 4 wk postpartum, the animals were examined twice weekly to monitor possible puerperal disorders, including retention of fetal membranes (RFM; not expelled in $24 \mathrm{~h}$ after the delivery) and uterine inflammations. Uterus (position, size, content) was examined by palpation per rectum and ultrasonography with a $7.5-\mathrm{MHz}$ rectal linear probe (Draminski, Profi L, Olsztyn, Poland), whereas the cervix (position, open or closed, diameter, color, exudate) and vagina (lesions, lacerations, pus, mucus) were examined using vaginoscopy. Body temperature was measured daily during the first $15 \mathrm{~d}$ postpartum. The diagnosis of puerperal uterine inflammation was established during the first $2 \mathrm{wk}$ in animals with a large and flaccid uterus, profusely reddish mucopurulent vaginal discharge, a uterus approximately larger than $30 \mathrm{~L}$, and a cervix open more than $10 \mathrm{~cm}$. The diagnosis of uterine inflammation was also established 3 wk postpartum if the cervix was open more than $8 \mathrm{~cm}$ and pus was evident (LeBlanc et al., 2002; Sheldon et al., 2006). During the second and third month after parturition the examination was performed once a week. Clinical endometritis (CE) was diagnosed in cows with purulent vaginal discharge during estrus, and in cows with purulent or mucopurulent uterine discharge detectable externally or in the anterior vagina or with a cervical diameter greater than $7.5 \mathrm{~cm}$, a uterine horn diameter greater than $8 \mathrm{~cm}$, thickened uterine mucosa $(>1 \mathrm{~cm})$, or with the presence of liquid material in the uterus during metestrus (LeBlanc et al., 2002; Kasimanickam et al., 2004).

The voluntary waiting period for AI was $50 \mathrm{~d}$. Thereafter estrus was induced with $0.5 \mathrm{mg}$ of cloprostenol i.m. (PGF Veyx Forte $0.25 \mathrm{mg} / \mathrm{mL}$, Veyx GmBH, Schwarzenborn, Germany), or, in the case of anestrus, $50 \mu \mathrm{g}$ of depherelin (Depherelin Gonavet Veyx $50 \mu \mathrm{g} / \mathrm{mL}$, Veyx $\mathrm{GmBH}$ ) was administered. All animals were AI 12 to 18 $\mathrm{h}$ after the first signs of estrus and thereafter daily until ovulation was confirmed by palpation per rectum. The semen used was frozen-thawed and collected from only 1 bull, to minimize the influence of the bull, and was deposited into the uterine horn ipsilateral to the ovary bearing a dominant follicle. Pregnancy was confirmed 35 to $50 \mathrm{~d}$ after the last AI using ultrasonography. The number of AI until pregnancy and days open were recorded.

\section{Statistical Analysis}

Data were analyzed with PASW Statistics18 (SPSS, IBM, Armonk, NY). The effects of treatment (group), parity (cow or heifer), calf weight and sex, and dilatation of cervix and vulva at the first examination on the outcomes were each separately analyzed using logistic regression. The possible herd effect, as a random factor, was analyzed separately, but no statistically significant effects were found, thus herd effect was discarded from the analysis. Before the analyses, the continuous variables, time from the first examination to delivery and days open, were transformed to binary form as time $\leq 90$ or $>90 \mathrm{~min}$ and days open $<70$ or $\geq 70 \mathrm{~d}$. The ease of calving was classified in 2 ways, as the parameter "Assistance" (i.e., no assistance vs. any kind of assistance) and as the parameter "Stage II assistance" (i.e., no assistance or stage I assistance vs. stage II assistance). In the backward, stepwise elimination procedure, the nonsignificant variables $(P>0.15)$ were removed from the model. The variable "Time from the first examination to delivery" was problematic due to its dualistic nature. It can be seen as an outcome of the independent variables, but can also be an independent variable itself for some outcome parameters. Finally, it was removed from the list of independent variables because it was considered to be more a consequence of than a reason for many outcome variables (e.g., for stage II assistance). In the case of a significant difference, the magnitude and direction of the effect were indicated with an odds ratio $(\mathbf{O R})$. Possible differences were considered significant at $P<0.05$.

\section{RESULTS}

Table 1 details the independent factors, length of gravidity, calf weight at birth, proportion of male calves, and dilatation of birth canal at the first examination expressed as means $( \pm \mathrm{SD})$ or percentages, which may have had an effect on the outcomes among all animals in groups $\mathrm{T}$ and $\mathrm{C}$, as well as separately for cows and heifers. Table 2 indicates the effects of the treatment protocols on dependent variables studied, presented as proportions or means $( \pm \mathrm{SD})$ between all animals in groups $\mathrm{T}$ and $\mathrm{C}$, as well as for cows and heifers separately. The statistical significances of these effects and the effects of all independent variables are shown in Table 3. In the case of statistical significance the magnitude and direction of the difference is given as OR.

The treatment protocol had a significant effect on several dependent variables, indicating the ease of calving and reproductive health after parturition (Table 3) at least by increasing the number of animals with a birth canal dilated more than $25 \mathrm{~cm}$ (OR 8.3 to 10.0). In addition, the treatment approximately halved the need for assistance at parturition, from 88 to $46 \%$ (OR $=9.4^{-1}$ ) , and decreased the incidence of stage II assistance $\left(\mathrm{OR}=6.2^{-1}\right)$. Furthermore, the treatment protocol decreased the need for episiotomy, the appearance of birth canal lesions, and the incidence of CE. The risks 
Table 1. The mean $( \pm \mathrm{SD})$ length of gravidity, calf weight at birth, and proportion of male calves for all animals in groups $\mathrm{T}$ (treatment) and $\mathrm{C}$ (control) as well as separately for cows and heifers, and the stage of dilatation of birth canal, cervix and vulva at the first examination expressed as a percentage of animals exceeding $20 \mathrm{~cm}$

\begin{tabular}{|c|c|c|c|c|c|c|}
\hline Item & \multicolumn{2}{|c|}{ All animals } & \multicolumn{2}{|c|}{ Cow } & \multicolumn{2}{|c|}{ Heifer } \\
\hline Gravidity length, d & $283.5 \pm 5.0$ & $284.0 \pm 5.1$ & $285.7 \pm 5.2$ & $286.1 \pm 4.5$ & $281.2 \pm 3.5$ & $281.8 \pm 4.8$ \\
\hline Male calves, \% & 55 & 51 & 50 & 50 & 60 & 52 \\
\hline Cervix >20 cm, \% & 54 & 65 & 52 & 60 & 56 & 70 \\
\hline Vulva $>20 \mathrm{~cm}, \%$ & 52 & 51 & 36 & 84 & 68 & 18 \\
\hline
\end{tabular}

of calf mortality and RFM fell, but the effects were not statistically significant. The treatment protocol seemed to have an effect throughout the entire puerperal period because treated animals conceived after fewer AI (1.3 vs. $1.6 \mathrm{AI} /$ pregnancy) and became pregnant sooner (67 vs. 78 d) compared with control animals.

The parity (cow vs. heifer) did not significantly influence the need for assistance at parturition, nor the incidence of stage II assistance or lesions of the birth canal, although a slightly higher number of AI until pregnancy were recorded for cows compared with heifers (1.51 vs. 1.44). Calf birth weight had a significant effect on assistance requirements, but, interestingly, the lighter calves needed more help. Male calves increased the risk for stage II assistance, however. The dilatation of the birth canal at first examination immediately following arrival of the veterinarian did not appear to have a substantial effect on the dependent variables. This ap- plies especially to dilatation of the vulva because it had no significant effects on any of the variables studied. Dilatation of cervix at first examination exerted some influence, because if the cervix was already open more than $20 \mathrm{~cm}$ an increased need for assistance was noted, the incidence of stage II assistance increased, and the risk for RFM rose.

\section{DISCUSSION}

The present study was designed to identify means to reduce pain during parturition, thus improving cow and calf welfare. According to Garry (2004), the welfare aspect of dystocia has been virtually ignored in the US dairy industry. However, recent studies have implications for improving animal welfare. Recognition that cattle experience pain means that producers and veterinarians are obligated to minimize that pain.

Table 2. The effects of the treatment protocol (denaverine hydrochloride and carbetocin given in respect of the progression of the parturition) on the outcomes of the study, indicating the ease of calving and reproductive health thereafter in all animals in groups $\mathrm{T}$ (treatment) and $\mathrm{C}$ (control), as well as in cows and heifers separately; effects are expressed as percentages or means $( \pm \mathrm{SD})$

\begin{tabular}{|c|c|c|c|c|c|c|}
\hline \multirow[b]{2}{*}{ Item } & \multicolumn{2}{|c|}{ All animals } & \multicolumn{2}{|c|}{ Cow } & \multicolumn{2}{|c|}{ Heifer } \\
\hline & $\mathrm{T}$ & $\mathrm{C}$ & $\mathrm{T}$ & $\mathrm{C}$ & $\mathrm{T}$ & $\mathrm{C}$ \\
\hline Cervix $>25 \mathrm{~cm},{ }^{1} \%$ & 43 & 7 & 44 & 8 & 42 & 6 \\
\hline Vulva $>25 \mathrm{~cm},{ }^{2} \%$ & 44 & 9 & 58 & 8 & 30 & 10 \\
\hline Time, $\min$ & $71 \pm 29$ & $101 \pm 16$ & $74 \pm 30$ & $96 \pm 15$ & $68 \pm 28$ & $107 \pm 14$ \\
\hline Assistance, ${ }^{3} \%$ & 46 & 88 & 36 & 90 & 56 & 86 \\
\hline Stage II assistance, ${ }^{4} \%$ & 22 & 58 & 20 & 46 & 24 & 70 \\
\hline Episiotomy, \% & 4 & 22 & 4 & 16 & 4 & 28 \\
\hline Lesions, \% & 3 & 15 & 2 & 12 & 4 & 18 \\
\hline Calf mortality, $\%$ & 3 & 9 & 2 & 8 & 4 & 10 \\
\hline $\mathrm{RFM}^{5} \%$ & 12 & 22 & 16 & 24 & 8 & 20 \\
\hline $\mathrm{CE},{ }^{6} \%$ & 14 & 27 & 16 & 36 & 12 & 18 \\
\hline $\mathrm{AI}^{7}$ & $1.33 \pm 0.67$ & $1.62 \pm 0.76$ & $1.36 \pm 0.63$ & $1.66 \pm 0.69$ & $1.30 \pm 0.71$ & $1.58 \pm 0.84$ \\
\hline Days open, d & $67.0 \pm 11.2$ & $78.3 \pm 18.6$ & $68.0 \pm 12.1$ & $79.5 \pm 12.6$ & $66.0 \pm 10.1$ & $77.1 \pm 23.2$ \\
\hline
\end{tabular}

${ }^{1}$ Cervix dilated more than $25 \mathrm{~cm}$ at parturition.

${ }^{2}$ Vulva dilated more than $25 \mathrm{~cm}$ at parturition.

${ }^{3}$ Any kind of assistance (stages I and II).

${ }^{4}$ Moderate to hard traction.

${ }^{5} \mathrm{RFM}=$ retained fetal membranes.

${ }^{6} \mathrm{CE}=$ clinical endometritis.

${ }^{7}$ Number of artificial inseminations per pregnancy. 
Table 3. Statistical significances based on multivariable logistic regression of the effects of independent variables on the outcomes indicating the ease of calving and reproductive health thereafter ${ }^{1}$

\begin{tabular}{|c|c|c|c|c|c|c|}
\hline \multirow[b]{2}{*}{ Outcome } & \multicolumn{6}{|c|}{ Independent variable in the model } \\
\hline & $\begin{array}{c}\text { Group } \\
\text { (treatment) }\end{array}$ & $\begin{array}{c}\text { Cow/Heifer } \\
\text { (cow) }\end{array}$ & $\begin{array}{c}\text { Calf } \\
\text { weight }\end{array}$ & $\begin{array}{c}\text { Calf sex } \\
\text { (male) }\end{array}$ & $\begin{array}{l}\text { Cervix }>20 \mathrm{~cm} \\
\text { at first exam }\end{array}$ & $\begin{array}{l}\text { Vulva }>20 \mathrm{~cm} \\
\text { at first exam }\end{array}$ \\
\hline Vulva $>25 \mathrm{~cm}^{3}$ & $<0.001(8.3)$ & NS & $0.034(1.1)$ & NS & $0.009\left(2.6^{-1}\right)$ & NS \\
\hline Time & $0.031\left(1.9^{-1}\right)$ & NS & NS & NS & $\mathrm{NS}$ & NS \\
\hline Assistance $^{4}$ & $<0.001\left(9.4^{-1}\right)$ & NS & $0.010\left(1.1^{-1}\right)$ & NS & $0.022(2.2)$ & NS \\
\hline Lesions & $0.007\left(5.7^{-1}\right)$ & NS & NS & NS & $\mathrm{NS}$ & NS \\
\hline Calf mortality & $\mathrm{NS}$ & NS & NS & NS & NS & NS \\
\hline $\mathrm{RFM}^{6}$ & NS & NS & NS & NS & $0.012(3.1)$ & NS \\
\hline $\mathrm{CE}^{7}$ & $0.025\left(2.3^{-1}\right)$ & NS & NS & NS & $\mathrm{NS}$ & NS \\
\hline $\mathrm{AI}^{8}$ & $0.002\left(2.7^{-1}\right)$ & $0.023(2.0)$ & NS & NS & NS & NS \\
\hline Days open & $<0.001\left(5.0^{-1}\right)$ & NS & NS & NS & NS & NS \\
\hline
\end{tabular}

${ }^{1}$ In the case that the effect is statistically significant, the odds ratio is given in parentheses (with respect to the factor given in the heading; negative exponent indicates inverse correlation).

${ }^{2}$ Cervix dilated more than $25 \mathrm{~cm}$ at parturition.

${ }^{3}$ Vulva dilated more than $25 \mathrm{~cm}$ at parturition.

${ }^{4}$ Any kind of assistance (Stages I and II).

${ }^{5}$ Moderate to hard traction.

${ }^{6} \mathrm{RFM}=$ retained fetal membranes.

${ }^{7} \mathrm{CE}=$ clinical endometritis.

${ }^{8}$ Number of artificial inseminations.

Weary et al. (2006) highlighted the importance of effective pain measurement and the need to develop simple, repeatable techniques for objective and subjective pain assessment, as pain likely influences both individual and social behavior of affected animals.

Our results showed that DH and CT application resulted in significantly more animals having the vulva and cervix dilated more than $25 \mathrm{~cm}$ at parturition, translating to significantly fewer animals suffering from dystocia, requiring episiotomy, or having postpartum birth canal lesions in comparison with control animals. The effects of the birth canal softening are supported by previous reports that $\mathrm{DH}$ has a pronounced spasmolytic effect, mainly musculotropic, which is stronger than that of papaverine at a level of analgesic efficacy of between 40 and $90 \%$ morphine strength (Cort et al., 1979, 1981; Sobiraj et al., 1998; Bajcsy et al., 2005; Handler et al., 2006). In addition, the same authors reported that $\mathrm{DH}$ reduces the tension in the soft birth canal tissues in cattle when administered toward the end of the opening stage or at the dilation stage, which is recognizable as a relaxation of the hard and tense vulvar and cervical tissue. To our knowledge the current study is the first that links these findings in the ease of calving and its positive consequences, however.

As shown, application of DH and CT acted beneficially, improving welfare by decreasing the number of animals suffering from difficult calving, decreasing the time required for delivery, decreasing the number of animals requiring episiotomy, and reducing numbers with postcalving birth canal lesions. Dystocia affects the profitability of herds, animal welfare, and acceptability of the production system by consumers (Carnier et al., 2000); likewise, dystocia negatively affects reproductive traits, resulting in 32 more days open and 0.5 more AI until pregnancy compared with unaffected animals (Dematawewa and Berger, 1997). Administration of $\mathrm{DH}$ and $\mathrm{CT}$ in the present study resulted in significantly fewer animals having postpartum birth canal lesions, which significantly decreased the risk of $\mathrm{CE}$. The reduced number of days open and number of AI until pregnancy as a result of fewer cases of CE is in concordance with the reports of Opsomer et al. (2000) and Sheldon et al. (2002).

Administration of $\mathrm{DH}$ and $\mathrm{CT}$ during parturition acted beneficially on puerperal health and fertility. These results are supported by the findings of Laster et al. (1973) and Echternkamp and Gregory (1999), with dystocia increasing the number of days open and decreasing conception rate in Hereford, Angus, and Holstein-Friesian breeds. No relationship between parity and stage II assistance was established in our study, and is not in accordance with the reports of Meyer et al. (2001), Berglund et al. (2003), and Lombard et al. (2007), which indicated that primiparous cows are at a higher risk of stillbirths and dystocia. Discrepancies between our results and the cited reports are, most likely, the result of breed influence, with only animals of the Simmental breed being included in the current study. As reported by Colnar et al. (2008) and Zobel (2013), 
the incidence of any kind of assistance ranged from 11 to $69 \%$ for Simmental cows in Croatia, being highly correlated with the BCS of cows and the characteristics of the sire. At the same time, dystocia was recorded only 1.2 times more often in pluriparous cows compared with primiparous (Vrbanić, 2009; Zobel, 2013) and thus is in agreement with the findings of the current study.

Retained fetal membranes were recorded in 12 and $22 \%$ of animals within groups $\mathrm{T}$ and $\mathrm{C}$, respectively. This is in agreement with the previous reports of Colnar et al. (2008), Zobel (2013), and Zobel and Tkalčić (2013), who reported the incidence of RFM being between 9 and $28 \%$ in Croatian Simmental cows. In our study, 3 and $9 \%$ of calves died during the first $24 \mathrm{~h}$ after birth in groups $\mathrm{T}$ and $\mathrm{C}$, respectively, similar to Colnar et al. (2008), who reported $6.3 \%$ of calves dead within $24 \mathrm{~h}$ following birth for Simmental cows in Croatia. Clinical endometritis was diagnosed in 14 and $27 \%$ of animals in groups $\mathrm{T}$ and $\mathrm{C}$, respectively, in our study and is in agreement with Zobel (2013) and Zobel et al. (2013), who reported a CE incidence of 16.8 to $29.3 \%$ for Simmental cows in Croatia.

Interestingly, a negative correlation between calf weight and the need for assistance was recorded, with lighter calves needing greater assistance. Despite the statistical significance, the OR were very low and thus of no practical relevance.

Our concern was that the present study was not conducted blind for practical reasons. To avoid possible bias as a consequence of this drawback, all the procedures used in the study were planned to be as objective as possible. All the waiting periods were strictly fixed and the measurements individualized and synchronized. However, a need for further studies of double-blind design remains in order to confirm our findings. The optimal timing and number of injections, both $\mathrm{DH}$ and $\mathrm{CT}$, in respect to the progression of labor were not within the scope of the current study, and thus no recommendations can be given at this stage. One challenge in the application of the treatment in practice is that veterinarians are most often called to urgent cases of parturition, where obstetrical manipulations are requested immediately without any time to wait for the effect of DH. For example, a rapid increase in herd size globally may change the situation so that educated staff on duty could administer the treatments according to instructions. Nevertheless, practical applications of this treatment remain to be investigated in further studies.

\section{CONCLUSIONS}

Our results support a positive influence of $\mathrm{DH}$ on the softening of the birth canal and dilatation of the cervix and vulva, with CT increasing myometrial contractility.
The combined effects obtained in the Simmental breed resulted in a shorter parturition period, decreased the need for assistance during labor and the risk of dystocia (stage II assistance), and, as a consequence, decreased the incidence of birth canal lesions and CE. To the best of our knowledge, this is the first indication of the effect of this treatment, DH and CT given during parturition, on the progression and ease of calving, and thus on the welfare of cows in labor. However, further studies of a double-blind design should be performed to confirm the findings, and studies are needed to establish best practices.

\section{ACKNOWLEDGMENTS}

The authors wish to thank Vlatka Buić and Ivana Pipal (Vetmed d.o.o., Popovača, Croatia) for their valuable contribution and help in the collection of the material.

\section{REFERENCES}

al-Eknah, M. M., and A. M. Homeida. 1991. A review of some aspects of the pharmacology of oxytocin in domestic animals. Vet. Res. Commun. 15:45-55.

Arthur, G. H. 1979. Retention of the after birth in cattle: A review and commentary. Vet. Annu. Can. Vet. J. 19:26-36.

Bajcsy, A. C., O. SzenciDoornenbal, A., G. C. van der Weijden, C. Csorba, L. Kocsis, I. Szucs, S. Ostgard, and M. A. Taverne. 2005. Characteristics of bovine early puerperal uterine contractility recorded under farm conditions. Theriogenology 64:99-111.

Berglund, B., L. Steinbock, and M. Elvander. 2003. Causes of stillbirth and time of death in Swedish Holstein calves examined post mortem. Acta Vet. Scand. 44:111-120.

Bernhard, A., J. Schulz, S. Gutjahr, and K. Eulenberger. 1993. Indikationen für die Anwendung eines Depotoxytozin-Präparates in der tierärztlichen Praxis. Tierarztl. Umsch. 48:446-453.

Carnier, P., A. Albera, R. Dal Zotto, A. F. Groen, M. Bona, and G. Bittante. 2000. Genetic parameters for direct and maternal calving ability over parities in Piedmontese cattle. J. Anim. Sci. 78:2532-2539.

Colnar, S., M. Samardžija, I. Žagar, M. Tomac, N. Murvin, M. Mihelčić, T. Karadjole, and A. Tomašković. 2008. Frequency of dystocia and methods of helping with calvings in cows and heifers between year 2005 and year 2009 (in Croatian). Veterinarska stanica 39:207-217.

Cort, N., S. Einarsson, D. Schams, and H. Vilhardt. 1981. Blood concentrations of oxytocin equivalents after single injections of deamino-1-monocarba-[2-O-methyltyrosine]-oxytocin in lactating sows. Am. J. Vet. Res. 42:1804-1806.

Cort, N., S. Einarsson, and S. Viring. 1979. Actions of oxytocin and a long-acting carba oxytocin analog on the porcine myometrium in vitro and in vivo. Am. J. Vet. Res. 40:430-432.

Dematawewa, C. M. B., and P. J. Berger. 1997. Effect of dystocia on yield, fertility and cow losses and an economic evaluation of dystocia scores for Holsteins. J. Dairy Sci. 80:754-761.

Drillich, M., N. Klever, and W. Heuwieser. 2007. Comparison of two management strategies for retained fetal membranes on small dairy farms in Germany. J. Dairy Sci. 90:4275-4281.

Echternkamp, S. E., and K. E. Gregory. 1999. Effects of twinning on gestation length retained placenta, and dystocia. J. Anim. Sci. $77: 39-47$.

Edmonson, A. J., I. J. Lean, L. D. Weaver, T. Farver, and G. Webster. 1989. A body condition scoring chart for Holstein dairy cows. J. Dairy Sci. 72:68-78. 
Egan, J., N. Leonard, J. Griffin, A. Hanlon, and D. Poole. 2001. A survey of some factors relevant to animal welfare on 249 dairy farms in the Republic of Ireland. Part 1. Data on housing, calving and calf husbandry. Ir. Vet. J. 54:388-392.

Eulenberger, K., J. Wilhelm, J. Schulz, S. Gutjahr, K. Wohanka, and H. Däberitz. 1986. Uterotonika im Puerperium des Rindes. Monatsh. Veterinarmed. 41:371-377.

Fields, M. J., and P. A. Fields. 1996. Morphological characteristics of the bovine corpus luteum during the estrous cycle and pregnancy. Theriogenology 45:1295-1325.

Fourichon, C., H. Seegers, and X. Mahler. 2000. Effect of dystocia on reproduction in the dairy cow: A meta-analysis. Theriogenology $53: 1729-1759$

Garry, F. B. 2004. An overview of animal welfare in the US dairy industry. Bov. Pract. 38:1-22.

Gundelach, Y., K. Essmeyer, M. K. Teltscher, and M. Hoedemaker. 2009. Risk factors for perinatal mortality in dairy cattle: Cow and foetal factors, calving process. Theriogenology 71:901-909.

Handler, J., D. Hoffman, F. Weber, D. Schams, and C. Aurich. 2006. Oxytocin does not contribute to the effects of cervical dilation on progesterone secretion and embryonic development in mares. Theriogenology 66:1397-1404.

Hickey, G. J., M. E. White, R. P. Wickenden, and D. A. Armstrong. 1984. Effects of oxytocin on placental retention following dystocia. Vet. Rec. 114:189-190.

Hüller, H. 1970. Pharmakologie und Klinik von O-(2-Äthylbutoxy)benzilsäure-2-dimethyla minoäthylesterhydrochlorid (Spasmalgan). Zentralbl. Pharm. Pharmakother. Laboratoriumsdiagn. 109:115-139.

Huxley, J. N., and H. R. Whay. 2006. Current attitudes of cattle practitioners to pain and the use of analgesics in cattle. Vet. Rec. 159:662-668.

Kasimanickam, R., T. F. Duffield, R. A. Foster, C. J. Gartley, K. E. Leslie, J. S. Walton, and W. H. Johnson. 2004. Endometrial cytology and ultrasonography for the detection of subclinical endometritis in postpartum dairy cows. Theriogenology 62:9-23.

Laster, D. B., H. A. Hudson, L. V. Cundiff, and K. E. Gregory. 1973. Factors affecting dystocia and the effects of dystocia on subsequent reproduction in beef cattle. J. Anim. Sci. 36:695-705.

LeBlanc, S. J. 2008. Postpartum uterine disease and dairy herd reproductive performance: A review. Vet. J. 176:102-114.

LeBlanc, S. J., T. F. Duffield, K. E. Leslie, K. G. Batean, G. P. Keefe, J. S. Walton, and W. H. Johnson. 2002. Defining and diagnosing postpartum clinical endometritis and its impact on reproductive performance in dairy cows. J. Dairy Sci. 85:2223-2236.

Lombard, J. E., F. B. Garry, S. M. Tomlinson, and L. P. Garber. 2003. Relationship of dystocia to dairy cow health and productivity. J. Dairy Sci. 86(Suppl. 1):32.

Lombard, J. E., F. B. Garry, S. M. Tomlinson, and L. P. Garber. 2007. Impacts of dystocia on health and survival of dairy calves. J. Dairy Sci. 90:1751-1760.

MacKenzie, I. Z., and E. Burns. 1997. Randomised trial of one versus two PGE2 doses for induction of labour: 1. Clinical outcome. Br. J. Obstet. Gynaecol. 104:1062-1067.

McClintock, S. E. 2004. A genetic evaluation of dystocia in Australian Holstein-Friesian cattle. PhD Thesis. Univ. Melbourne, Melbourne, Australia.

Mee, J. F. 2004. Managing the dairy cow at calving time. Vet. Clin. North Am. Food Anim. Pract. 20:521-546.

Mee, J. F. 2008. Prevalence and risk factors for dystocia in dairy cattle: A review. Vet. J. 176:93-101.
Mee, J. F., D. P. Berry, and A. R. Cromie. 2008. Prevalence of, and risk factors associated with, perinatal calf mortality in pasturebased Holstein-Friesian cows. Animal 2:613-620.

Meyer, C. L., P. J. Berger, K. J. Koehler, J. R. Thompson, and C. G. Sattler. 2001. Phenotypic trends in incidence of stillbirth for Holsteins in the United States. J. Dairy Sci. 84:515-523.

Miller, B. J., and J. R. Lodge. 1984. Postpartum oxytocin treatment for prevention of retained placentas. Theriogenology 22:385-388.

Mollo, A., M. C. Veronesi, F. Cairoli, and F. Soldano. 1997. The use of oxytocin for the reduction of cow placental retention, and subsequent endometritis. Anim. Reprod. Sci. 48:47-51.

Oltenacu, P. A., A. Frick, and B. Lindhe. 1988. Use of statistical modeling and decision analysis to estimate financial losses due to dystocia and other disease in Swedish cattle. Pages 353-355 in Proc. 5th Int. Sym. Vet. Epidemiol. Econ., Copenhagen, Denmark.

Opsomer, G., Y. T. Grohn, J. Hertl, M. Coryn, H. Deluyker, and A. de Kruif. 2000. Risk factors for postpartum ovarian dysfunction in high producing dairy cows in Belgium: A field study. Theriogenology 53:841-857.

Roberts, S. J. 1986. Veterinary obstetrics and genital diseases. Pages 126-284 in Theriogenology. 3rd ed. S. J. Roberts, Woodstock, Vermont. Distributed by David and Charles Inc., North Pomfret, VT.

Scharein, E., and B. Bromm. 1998. The intracutaneous pain model in the assessment of analgesic efficacy. Pain Rev. 5:216-246.

Sheldon, I. M., G. S. Lewis, S. LeBlanc, and R. O. Gilbert. 2006. Defining postpartum uterine disease in cattle. Theriogenology 65:1516-1530

Sheldon, I. M., D. E. Noakes, A. N. Rycroft, D. U. Pfeiffer, and H. Dobson. 2002. Influence of uterine bacterial contamination after parturition on ovarian dominant follicle selection and follicle growth and function in cattle. Reproduction 123:837-845.

Sobiraj, A., A. Hermülheim, K. Herfen, and S. Schulz. 1998. Einfluß verschiedener Uterotonika auf den Nachgeburtsabgang bei Rindern nach konservativen und operativen geburtshilflichen Eingriffen. Tierarztl. Umsch. 53:392-399.

Squire, A. G. 1980. Therapy for retained placenta. Pages 186-189 in Current Therapy in Theriogenology: Diagnosis, Treatment and Prevention of Reproductive Diseases in Animals. D. A. Morrow, ed., W.B. Saunders, Philadelphia, PA.

Staab, A., B. S. Schug, V. Larsimont, M. Elze, D. Thummler, E. Mutschler, and H. Mlume. 2003. Pharmacokinetics and bioavailability of denaverine hydrochloride in healthy subjects following intravenous, oral and rectal single doses. Eur. J. Pharm. Sci. 18:121-128.

Vrbanić, D. 2009. Frequency of dystocia in cows and heifers in the area of Veterinary Ambulance Roman d.o.o. Đakovo (in Croatian). Graduate thesis, University of Zagreb, Zagreb, Croatia.

Weary, D. M., L. Niel, F. C. Flower, and D. Fraser. 2006. Identifying and preventing pain in animals. Appl. Anim. Behav. Sci. 2:64-76.

Whay, H. R., C. D. Hudson, and J. N. Huxley. 2008. Where are we with pain recognition and management in cattle? Am. Assoc. Bov. Pract. Proc. 41:54-59.

Zobel, R. 2013. Endometritis in Simmental cows: Incidence, causes, and therapy options. Turk. J. Vet. Anim. Sci. 37:134-140.

Zobel, R., and S. Tkalčić. 2013. Efficacy of ozone and other treatment modalities for retained placenta in dairy cows. Reprod. Domest. Anim. 48:121-125.

Zobel, R., S. Tkalčić, and W. J. Colle. 2013. Fertility issues in Simmental cows in central Croatia: A 5-year study. Turk. J. Vet. Anim. Sci. $37: 454-461$. 